\title{
Electrochemical Impedance Spectroscopy (EIS) and Study of Iron Corrosion Inhibition by Turmeric Roots Extract (TRE) in Hydrochloric Acid Solution
}

\author{
Kholod Almzarzie, Ahmad Falah", Ayman Massri and Hassan Kellawi \\ Department of Chemistry, Faculty of Science, Damascus University, Syria.
}

\begin{abstract}
$\mathbf{T}$ URMERIC Root extract (TRE) was tested as corrosion inhibitor for iron in $0.5 \mathrm{M} \mathrm{HCl}$, using potentiodynamic polarization and electrochemical impedance spectroscopy (EIS). Scanning electron microscope (SEM), and energy dispersive X-rays (EDX) analysis. The inhibition efficiency raised as in time of immersion rises, but decreases with temperature rise. The Nyquist plots showed that, the charge transfer resistance (Rct) increase, and the double layer capacitance $\left(\mathrm{C}_{\mathrm{dl}}\right)$ decreases with time of immersion increase. Tafel results exhibit that both corrosion current and with corrosion speed are reduced with time of immersion. All impedance spectra of EIS tests exhibit one capacitive loop which indicates that the corrosion reaction is controlled by charge transfer process. IE (\%) increases with the concentration of the inhibitor reaching its maximum value, $88.90 \%$, at $8 \mathrm{~g} / 100 \mathrm{ml}$. Thermodynamics parameters: $\mathrm{Ea}, \Delta \mathrm{H}^{*}$, $\Delta \mathrm{S}^{*}$ were estimated, and mechanism of corrosion and inhibition was discussed. The adsorption of (TRE) followed Langmuir adsorption isotherm.
\end{abstract}

Keywords: Iron, Electrochemical Impedance Spectroscopy (EIS), Turmeric Root extract (TRE), double layer capacitance $\left(\mathrm{C}_{\mathrm{dl}}\right)$, Scanning electron microscope (SEM).

\section{Introduction}

Inhibition of corrosion of iron is demanding for theoretical and practical aspects [1]. Iron and its alloys are of great importance in the industry, prompting vast research on corrosion resistant and its conducts [2]. Acids are wildly used in industries [3], such as industrial acid cleaning, acid descaling, acid picking, and used to remove mill scale from metallic surfaces. Natural compounds containing sulphur, oxygen and nitrogen atoms are effective as corrosion inhibitors in acid media, Inhibitors are used to reduce the rate of dissolution of metals [4]. Organic compounds containing heteroatoms are commonly used to reduce the corrosion process of iron in acidic media [5]. The use of non-toxic inhibitors called green or ecofriendly environmental inhibitors is one of the solutions possible to prevent corrosion of molten [6]. The adsorption of these compounds is influenced by the Electronic structure of their content of active compounds, electrons density, aromatic rings, and functional groups possessing free electrons such as, $\mathrm{R}-\mathrm{OH}-\mathrm{CHO},-\mathrm{N}=\mathrm{N}$ etc.., [7]. The adsorption of organic inhibitors at the metal/solution interface takes place through the replacement of water molecules by organic inhibitors molecules [8]. The efficiency of these compounds depends mainly on their abilities to be adsorbed on the metal surface with their polar groups moving as the reactive centers. The purpose of this research is to use a non-toxic environment-friendly inhibitor formed from Turmeric Root extract to reduce iron corrosion and study its effect using electrochemical Impedance and Tafel polarization methods.

\section{Materials and Methods}

Preparation of plant extract

The turmeric extract is prepared by washing, drying the turmeric root and grinding it then dissolving $1 \mathrm{~g}$ of powder in $100 \mathrm{ml}$ methanol $50 \%$, and removing the solvent by placing the solution in the vacuum evaporator, at $60^{\circ} \mathrm{C}$. Distilled water is used in the preparation process [9].

\section{Preparation of metal specimen}

The iron specimens having composition (wt $\%$ ) of $0.200 \% \mathrm{C}, 0.500 \% \mathrm{Si}, 1.600 \% \mathrm{Mn}, 0.035 \%$ $\mathrm{S}, 0.035 \% \mathrm{P}, 0.040 \mathrm{Nb}, 0.012 \mathrm{~N}, 0.020 \mathrm{Al}$, and remaining Fe were abraded with a series of emery papers 400,1200,1500, 2000 grades. The samples

*Corresponding author e-mail: prof_ahmad_falah@hotmail.com 
were then washed thoroughly with distilled water, and dried with air.

\section{Test Solution}

A solution of $0.5 \mathrm{M}$ concentrated acid was prepared using distilled water and $37 \%$ hydrochloric acid.

\section{Electrochemical Measurements}

Electrochemical measurements were carried out using potentiostat IVIUM-STAT.XR (Holland) piloted by voltammetry software. A three electrodes cell system containing working electrode (iron coupon) of a $1 \mathrm{~cm}^{2}$ exposed area, saturated $\left(\mathrm{Ag} / \mathrm{AgCl}_{2}\right)$ electrode as a reference electrode and a platinum wire as auxiliary electrode were used. The electrochemical impedance spectroscopy (EIS) measurements were carried out using the above electrochemical system, polarization curves were recorded at a sweep rate of $50 \mathrm{mV} \cdot \mathrm{s}^{-1}$, Electrochemical impedance spectroscopy (EIS) measurements were carried out at open-circuit potential over a frequency range of $1 \mathrm{MHz}-1 \mathrm{~Hz}$. The sinusoidal perturbation was amplitude of $0.01 \mathrm{mv}$.

Scanning electron microscopy (SEM), Energy dispersive $X$-rays (EDX)

Inhibitor film formation of the extracts surface was studied and compound using SEM and EDX Technique.
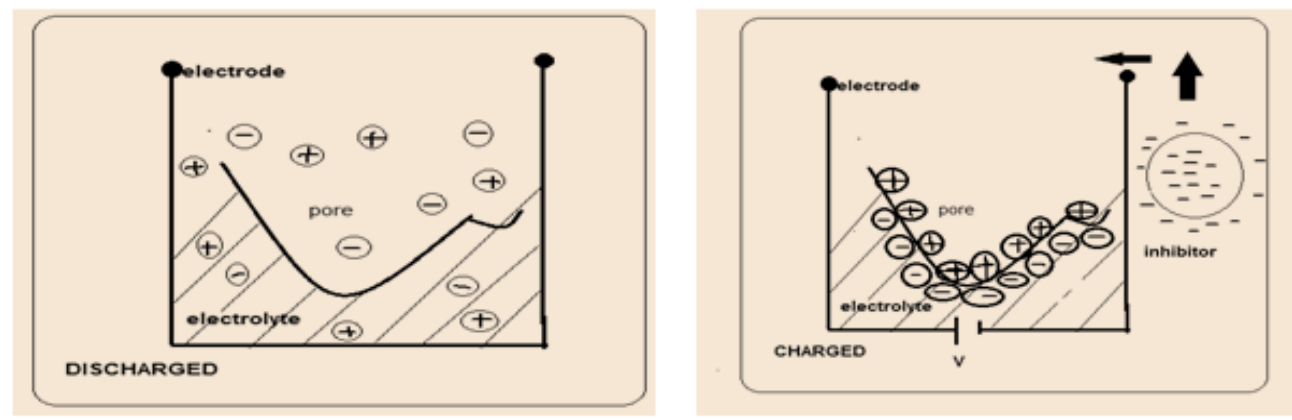

Fig. 1. Schematic presentation of the Electric Double-Layer formation.

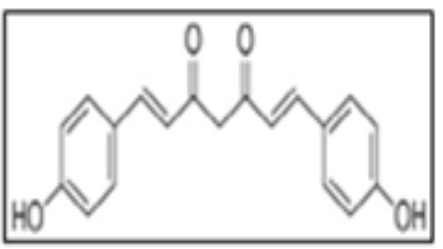

bis-demethoxv curcumin

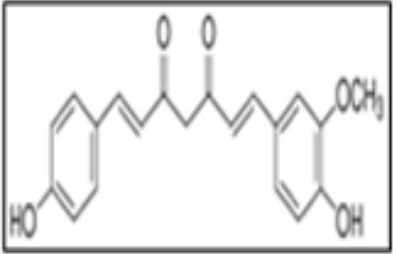

demethoxp curcumin

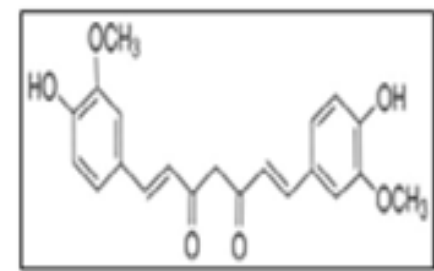

curcumin

Fig. 2. Active compounds in Turmeric Root extract (TRE).

Egypt.J.Chem. 62, No. 3 (2019) 


\section{Electrochemical impedance spectroscopy} measurements

The corrosion behavior of iron in $0.5 \mathrm{M} \mathrm{HCl}$ solution, in the absence and presence of TRE, it investigated by the EIS, at $298 \mathrm{~K}$ after 1 hour of immersion in the acid solution. The double layer capacitance $\left(\mathrm{C}_{\mathrm{dl}}\right)$ and the frequency at which the imaginary component of the impedance is maximum $\left(-Z_{\max }\right)$ are found via the equation:

$\mathrm{C}_{\mathrm{dl}}=1 / \mathrm{w}_{\text {max }} \mathrm{R}_{\mathrm{ct}} \quad$ where $\quad \mathrm{w}_{\text {max }}=2 \pi \mathrm{f}_{\text {max }}$

The inhibition efficiency $\% \mathrm{IE}_{\mathrm{Rct}}$ resulted from the charge transfer resistance $\left(\mathrm{R}_{\mathrm{ct}}\right)$ is calculated by:

$\% \mathrm{IE}_{\mathrm{Rct}}=\left[\left(\mathrm{R}_{\mathrm{ct}}-\mathrm{R}_{\mathrm{ct}}^{0}\right) / \mathrm{R}_{\mathrm{ct}}\right]_{*} 100$

where $\mathrm{R}^{0}$ and $\mathrm{R}_{\mathrm{ct}}$ are the charge transfer resistance $\left(\mathrm{R}_{\mathrm{ct}}\right)$ in the absence and presence of different concentrations of inhibitor, respectively [12].

Nyquist's and Bode's graphs of the results of the EIS of iron in $0.5 \mathrm{M} \mathrm{HCl}$, in absence and presence of different concentrations of TRE were presented in Fig. 3 and 4 respectively. The big capacitive loop refers to the adsorption of the inhibitor molecules (active compounds) presented in Fig. 2 on the iron samples [13]. The existence of single semi-circle indicated the single charge transfer process during dissolution which is unaffected by the presence of inhibitor molecules. Deviations of ideal circular shape are often referred to the frequency dispersion of interfacial impedance, which could be due to the roughness and other inhomogeneity of the surface, constant phase element (CPE) with the exponential factor $(\alpha)$ expressed about degree of roughness [14]. As seen in Table 1 , the $\mathrm{R}_{\mathrm{ct}}$ values of inhibited substrates increased with the concentration of inhibitors. Further, the values of $\mathrm{C}_{\mathrm{dl}}$ decreased which perhaps was compounds extract due to the decrease in local dielectric constant and/or increase in thickness of the electrical double layer, which suggests that TRE acts via adsorption at the metal/solution interface [15]. Equivalent circuit model used to fit impedance spectra data present in Fig. 5.

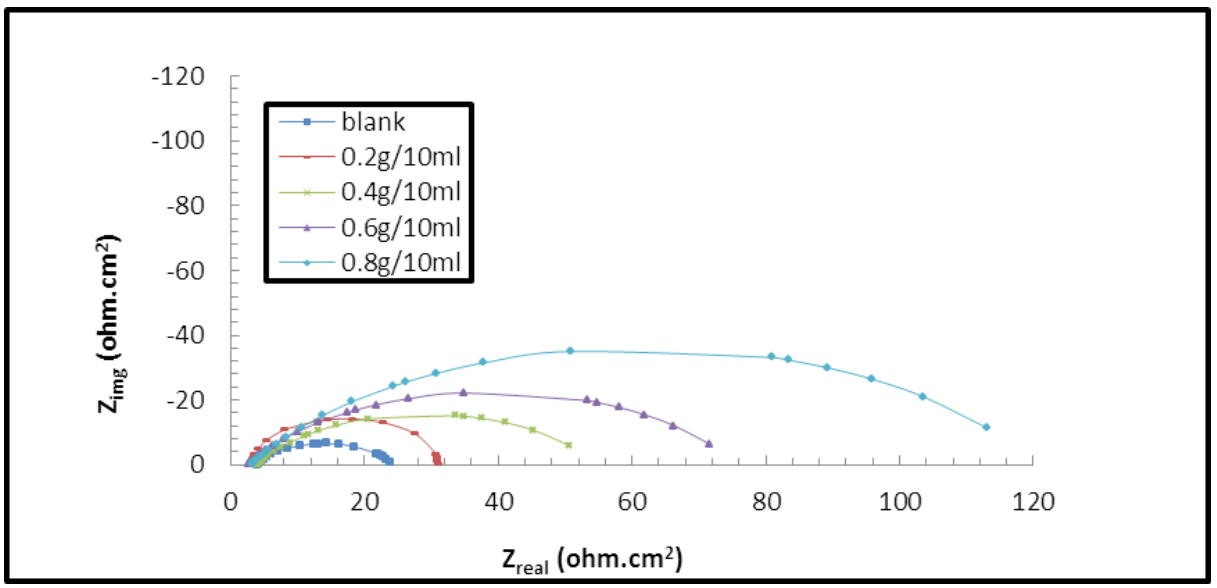

Fig. 3. Nyquist plots of iron in $0.5 \mathrm{M}$ HCl containing varying concentrations of TRE after 1hour of immersion in acid solution.
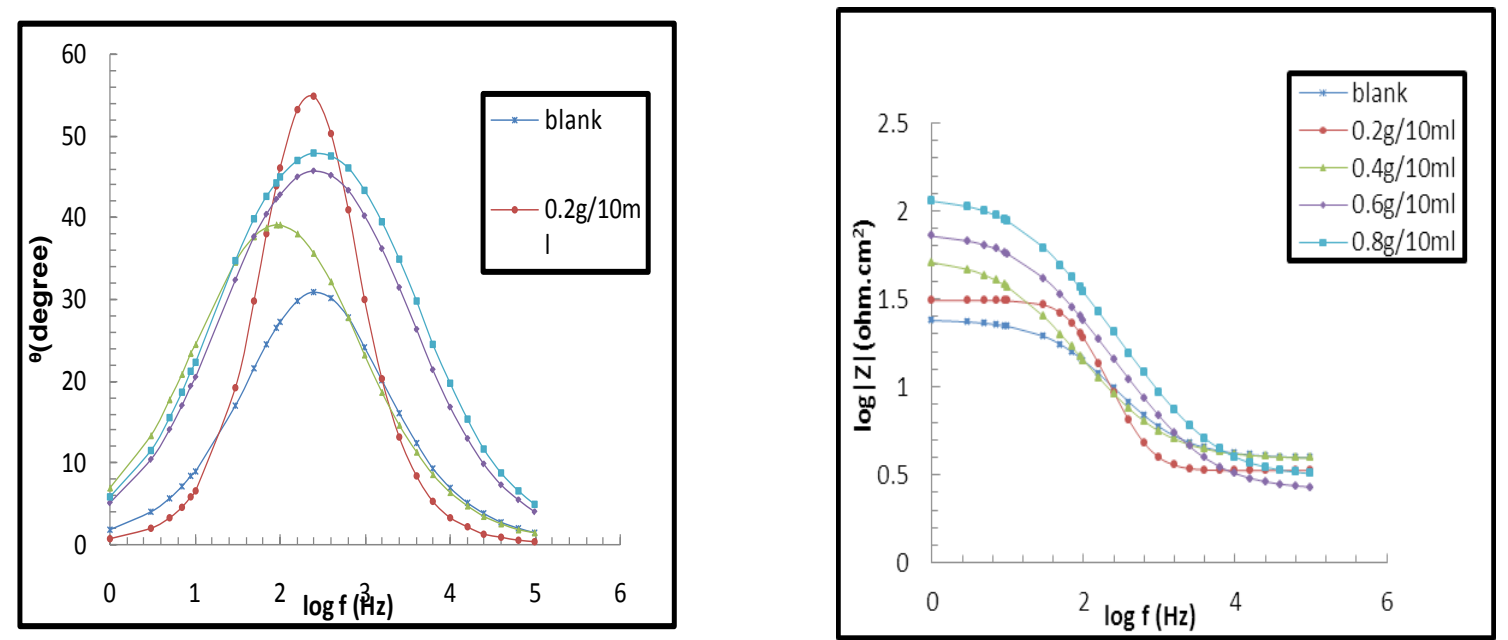

Fig. 4. Bode plots of iron in $0.5 \mathrm{M} \mathrm{HCl}$ containing varying concentrations of TRE after 1 hour of immersion in acid solution. 


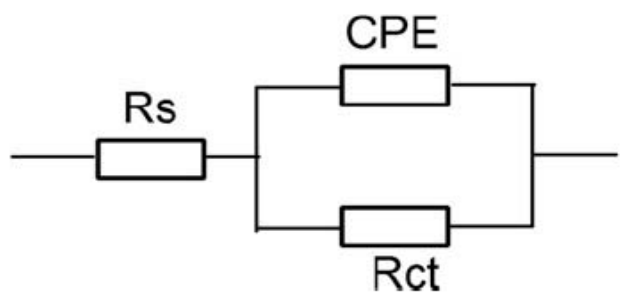

Fig. 5. Equivalent circuit model used to fit impedance spectra data.

TABLE 1. Impedance parameters of corrosion of iron in $0.5 \mathrm{M} \mathrm{HCl}$ at $298 \mathrm{~K}$ in the absence and presence of different concentrations of TRE.

\begin{tabular}{ccccccc}
\hline Inhibitor & $\begin{array}{c}\text { conc } \\
(\mathbf{g} / \mathbf{1 0 0} \mathbf{m l})\end{array}$ & $\begin{array}{c}\mathbf{R}_{\mathrm{ct}} \\
(\mathbf{o h m})\end{array}$ & $\begin{array}{c}\mathbf{f}_{\mathbf{m a x}} \\
\mathbf{( H z )}\end{array}$ & $\begin{array}{c}\mathbf{C}_{\mathbf{d l}} \\
\left(\mathbf{F} / \mathbf{c m}^{2}\right)\end{array}$ & $\mathbf{a}$ & $\mathbf{I E}_{\mathbf{R c t}} \mathbf{\%}^{\mathbf{0}}$ \\
\hline Blank & 0.0 & 20.3 & 160 & $4.90^{*} 10^{-5}$ & 0.73 & ------- \\
& 2.0 & 27.7 & 160 & $3.59 * 10^{-5}$ & 0.98 & 26.71 \\
Turmeric & 4.0 & 50.8 & 100 & $3.13^{*} 10^{-5}$ & 0.70 & 60.04 \\
Root extract & 6.0 & 73.1 & 160 & $1.36^{*} 10^{-5}$ & 0.70 & 72.23 \\
(TRE) & 8.0 & 117 & 160 & $8.51^{*} 10^{-6}$ & 0.70 & 82.65 \\
\hline
\end{tabular}

\section{Potentiodynamic polarization measurements}

Influence of concentration

Polarization measurements were done in order to know about the kinetics of the cathodic and anodic reactions. The anodic and cathodic currentpotential curves are extrapolated up to their intersection at appoint where corrosion current density $\left(\mathrm{I}_{\text {corr }}\right)$ and corrosion potential $\left(\mathrm{E}_{\text {corr }}\right)$ are acquired [16]. Table 2 shows the electrochemical parameters $\left(\mathrm{I}_{\text {corr }}, \mathrm{E}_{\text {corr }}, \beta \mathrm{a}, \beta \mathrm{c}\right.$, and $\mathrm{CR}$ ) obtained from Tafel plots for the iron electrode in $0.5 \mathrm{M} \mathrm{HCl}$ solution without and with various concentrations of TRE. The $\mathrm{I}_{\text {corr }}$ values were used to calculate the inhibition efficiency, IE (\%), in Table 2, using the following equation:

$\mathrm{IE}=\left[\mathrm{I}-\mathrm{I}_{\text {corr }} / \mathrm{I}\right]_{*} 100$ where $\mathrm{I}_{\text {corr }}$ and I are the corrosion current densities with presence and absence of inhibitor, respectively. The CR values in Table 2, using the following equation [17]:

$\mathrm{CR}=3.27 * 10^{-3} \mathrm{i}_{\text {corr }} \mathrm{E}_{\mathrm{w}} / \mathrm{d}$

where $i_{\text {corr }}$ is the corrosion current density in micro $\mathrm{A} / \mathrm{cm}^{2}, \mathrm{E}_{\mathrm{w}}$ is the equivalent weight of the corroding metal in grams, and $\mathrm{d}$ is the density of the corroding metal in $\mathrm{g} / \mathrm{cm}^{3}$.

Under the experimental conditions performed, the cathodic section of the plot represents the hydrogen evolution reaction, while the anodic section represents the iron dissolution reaction. They are determined by extrapolation of Tafel lines to the respective corrosion potentials.

TABLE 2. Electrochemical parameters of iron in $0.5 \mathrm{M} \mathrm{HCl}$ solution at different concentrations without and with TRE.

\begin{tabular}{|c|c|c|c|c|c|c|c|}
\hline Inhibitor & $\begin{array}{c}\text { conc } \\
(\mathrm{g} / 100 \mathrm{ml})\end{array}$ & $\begin{array}{c}-\mathrm{E}_{\text {corr }} \\
(\mathrm{mV} / \mathrm{SCE})\end{array}$ & $\begin{array}{c}I_{\text {corr }} \\
\left(A^{*} 10^{-4} / \mathrm{cm}^{2}\right)\end{array}$ & $\begin{array}{c}\beta a \\
(\mathrm{mV} / \mathrm{dec})\end{array}$ & $\begin{array}{c}\beta c \\
(\mathrm{mV} / \mathrm{dec})\end{array}$ & $\begin{array}{c}\text { CR } \\
(\mathrm{mm} / \mathrm{y})\end{array}$ & IE\% \\
\hline \multirow[t]{2}{*}{ Blank } & 0.0 & 0.677 & 26.13 & 0.352 & 0.183 & 8.56 & ---- \\
\hline & 2.0 & 0.3968 & 10.8 & 0.155 & 0.323 & 3.54 & 58.67 \\
\hline \multirow{3}{*}{$\begin{array}{c}\text { Turmeric } \\
\text { Root extract } \\
\text { (TRE) }\end{array}$} & 4.0 & 0.474 & 4.7 & 0.146 & 0.233 & 1.55 & 82.01 \\
\hline & 6.0 & 0.453 & 3.8 & 0.139 & 0.179 & 1.25 & 85.46 \\
\hline & 8.0 & 0.417 & 3.4 & 0.131 & 0.225 & 1.11 & 86.99 \\
\hline
\end{tabular}

The results in Table 2 indicates that the inhibitor reduces the corrosion current value and inhibition, IE (\%) increases with the concentration of the inhibitor reaching its maximum value,
88. $90 \%$, at $8 \mathrm{~g} / 100 \mathrm{ml}$. This result suggests that the mechanism of the electrode reaction is not changed [18].

Egypt.J.Chem. 62, No. 3 (2019) 
TABLE 3. Polarization parameters of iron in $0.5 \mathrm{M} \mathrm{HCl}$ at different temperatures with various concentration of TRE.

\begin{tabular}{|c|c|c|c|c|c|c|c|}
\hline $\mathbf{T}(\mathbf{K})$ & $\begin{array}{c}\text { Conc } \\
\text { (g/100ml) }\end{array}$ & $\begin{array}{c}-\mathbf{E}_{\text {corr }} \\
(\mathrm{mV} / \mathrm{SCE})\end{array}$ & $\begin{array}{c}I_{\text {corr }} \\
\left(\mu \mathbf{A} / \mathbf{c m}^{2}\right)\end{array}$ & $\begin{array}{c}\beta a(m V / \\
\text { dec) }\end{array}$ & $\begin{array}{c}\beta c(m V / \\
\text { dec })\end{array}$ & $\begin{array}{c}\mathrm{CR} \\
\mathrm{mm} / \mathrm{y}\end{array}$ & IE\% \\
\hline \multirow[t]{5}{*}{283} & Blank & 0.677 & 26.13 & 0.352 & 0.183 & 8.56 & ------- \\
\hline & 2 & 0.3968 & 10.8 & 0.155 & 0.323 & 3.54 & 58.67 \\
\hline & 4 & 0.468 & 5.9 & 0.148 & 0.177 & 1.933 & 77.42 \\
\hline & 6 & 0.453 & 3.8 & 0.139 & 0.179 & 1.25 & 85.46 \\
\hline & 8 & 0.442 & 2.9 & 0.143 & 0.188 & 0.979 & 88.90 \\
\hline \multirow[t]{5}{*}{293} & Blank & 0.661 & 31.1 & 0.316 & 0.174 & 10.19 & ------- \\
\hline & 2 & 0.379 & 8.35 & 0.142 & 0.328 & 2.73 & 73.15 \\
\hline & 4 & 0.458 & 6.6 & 0.138 & 0.205 & 2.167 & 78.78 \\
\hline & 6 & 0.458 & 4.8 & 0.164 & 0.206 & 1.581 & 84.57 \\
\hline & 8 & 0.441 & 4 & 0.131 & 0.193 & 1.318 & 87.14 \\
\hline \multirow[t]{5}{*}{303} & Blank & 0.677 & 33.8 & 0.331 & 0.168 & 11.07 & ------ \\
\hline & 2 & 0.452 & 13.5 & 0.167 & 0.249 & 4.4 & 60.06 \\
\hline & 4 & 0.426 & 9 & 0.132 & 0.263 & 2.97 & 73.37 \\
\hline & 6 & 0.474 & 7 & 0.152 & 0.193 & 2.29 & 79.29 \\
\hline & 8 & 0.498 & 5.7 & 0.14 & 0.16 & 1.87 & 83.14 \\
\hline \multirow[t]{5}{*}{313} & Blank & 0.714 & 36.2 & 0.378 & 0.119 & 11.84 & ------ \\
\hline & 2 & 0.477 & 14.6 & 0.188 & 0.237 & 4.788 & 59.67 \\
\hline & 4 & 0.419 & 11 & 0.135 & 0.28 & 3.631 & 69.61 \\
\hline & 6 & 0.379 & 7.9 & 0.133 & 0.339 & 2.6 & 78.18 \\
\hline & 8 & 0.468 & 5.9 & 0.148 & 0.177 & 1.933 & 83.70 \\
\hline
\end{tabular}

Influence of temperature

Polarization curves for the iron in $0.5 \mathrm{M} \mathrm{HCl}$ solution are shown in Fig. 6 and 7 in two different conditions, with constant concentrations of TRE and in the presence of different concentrations of TRE in the temperature range $283-313 \mathrm{~K}$.

The numerical values of the corrosion current density $\left(\mathrm{I}_{\text {corr }}\right)$, corrosion potential $\left(\mathrm{E}_{\text {corr }}\right)$, anodic Tafel slope ( $\beta \mathrm{a})$, cathodic Tafel slope $(\beta c)$, and the degree of surface coverage $(\Theta)$ vis the concentrations of inhibitor (TRE) at various temperatures are given in Table 3 . These values were calculated from the intersection of the cathodic and anodic Tafel lines of the polarisation curve at $\mathrm{E}_{\text {corr }}$. The surface overage $(\Theta)$ was calculated using:

$\Theta=\operatorname{IE~}(\%) / 100$

The inhibition efficiency IE (\%) is given by equation 3 .

The results of Table 3 refer that temperature increase leads to $\mathrm{I}_{\text {corr }}$, increase while the addition of TRE resulted in decrease of the $I_{\text {corr }}$ values across the temperature range. The results also indicate that the inhibition efficiencies increased with the concentration of inhibitor but decreased proportionally with temperature. Such behavior can be rationalized that the inhibitor acts by adsorption onto the metal surface [19].

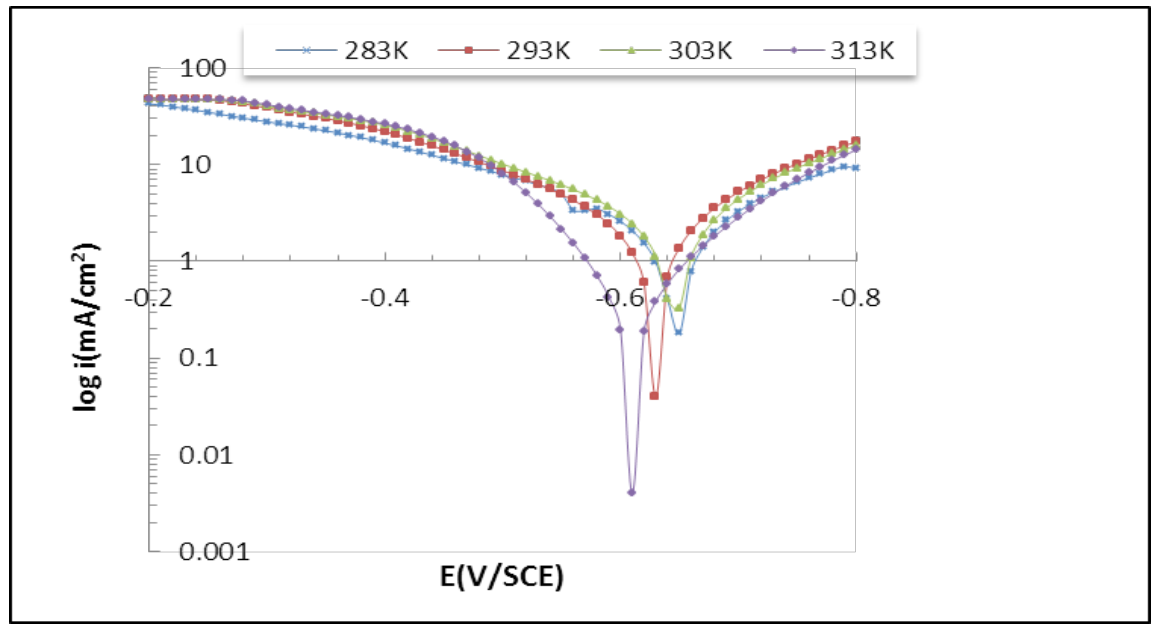

Fig. 6. polarization curves of iron in $0.5 \mathrm{M} \mathrm{HCl}$ at different temperatures. 


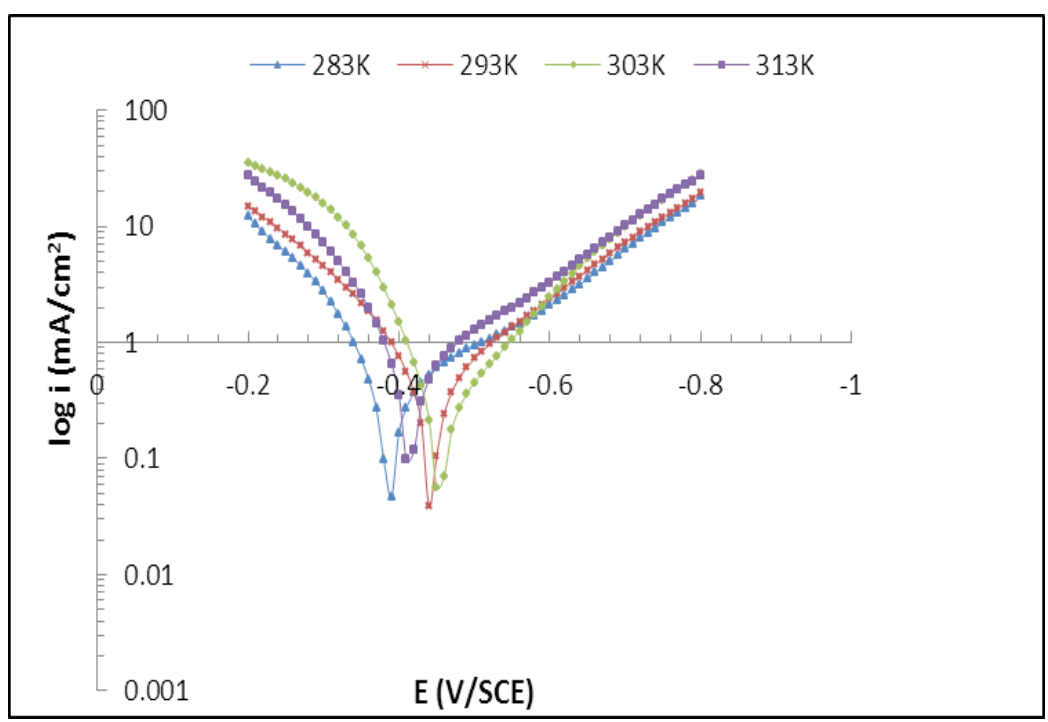

Fig. 7. polarization curves of iron in $0.5 \mathrm{M} \mathrm{HCl}$ at different temperatures in the presence of $8 \mathrm{~g} / 100 \mathrm{ml}$ of TRE.

Activation parameters such as the activation energy, Ea, the entropy of activation, $\Delta \mathrm{S}^{*}$, and the enthalpy of activation, $\Delta \mathrm{H}^{*}$, for both corrosion inhibition and corrosion of iron in $0.5 \mathrm{M} \mathrm{HCl}$ in the presence and absence of TRE at different concentrations between 283 and $313 \mathrm{~K}$ were calculated from an Arrhenius-type plot (Eq. 6) and transition state (Eq. 7) [20]:

$$
\log \left(\mathrm{I}_{\text {corr }}\right)=-\mathrm{E}_{\mathrm{a}} / 2.303 \mathrm{RT}
$$

where $I_{\text {corr }}$ is the corrosion current density (taken from averaged polarization), $\mathrm{Ea}$ is the activation energy, and $\mathrm{R}$ is the universal gas constant.

$$
\mathrm{I}=\frac{\mathrm{RT}}{\mathrm{Nh}} \exp \left(\frac{\Delta \mathrm{S} *}{\mathrm{R}}\right) \exp \left(-\frac{\Delta \mathrm{H} *}{\mathrm{RT}}\right)
$$

where h is Planck's constant, $\mathrm{N}$ is Avogadro's number, $\Delta \mathrm{H}^{*}$ is the enthalpy of activation, and $\Delta \mathrm{S}^{*} \mathrm{a}$ is the entropy of activation.

Plots of $\log \left(\mathrm{I}_{\text {corr }}\right)$ vs. 1/T and $\log \left(\mathrm{I}_{\text {corr }} / \mathrm{T}\right)$ vs. $1 / \mathrm{T}$ gave straight lines with slopes of $-\mathrm{Ea} / \mathrm{R}$ and $-\Delta H^{*} / R$, respectively. The intercepts were $A$ and $\left[\mathrm{Ln}(\mathrm{R} / \mathrm{Nh})+\left(\Delta \mathrm{S}^{*} / \mathrm{R}\right)\right]$ for the Arrhenius and transition state equations, respectively. (Fig. 8 and 9). The calculated values of the activation energy Ea, the entrpy of activation $\Delta \mathrm{S}^{*}$, and the enthalpy of activation $\Delta \mathrm{H}^{*}$ are presented in Table 4 .

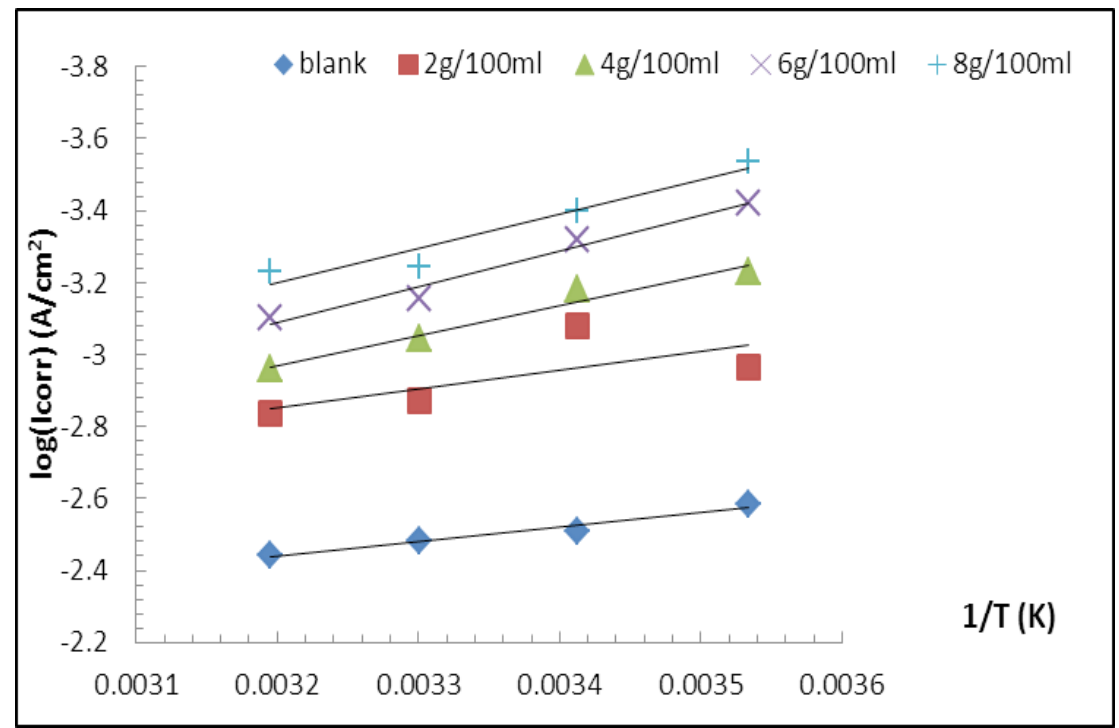

Fig. 8. Arrhenius plots of $\log \left(I_{\text {corr }}\right.$ versus $1 / T$ at various concentration of TRE. 


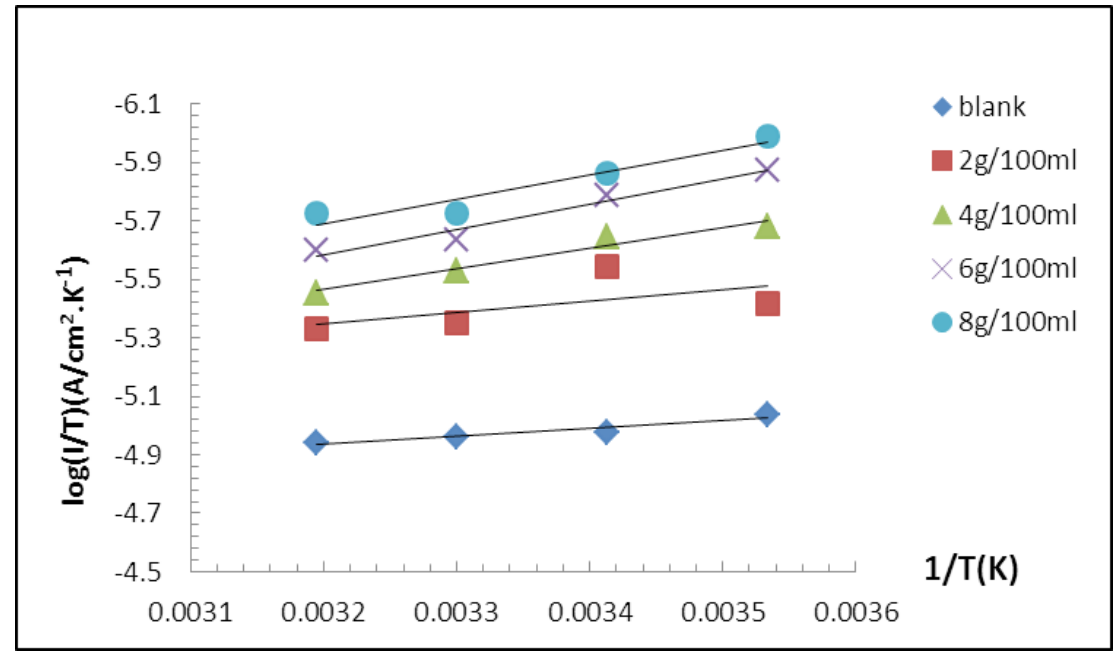

Fig. 9. variation of $\log \left(\mathrm{I}_{\text {corr }} / \mathrm{T}\right)$ versus $1 / \mathrm{T}$ at various concentrations of TRE.

The activation energy rises somewhat with increasing inhibitor concentration, suggesting adsorption of inhibitor molecules at the metal surface. The increase in the activation energy could be due to the corrosion reaction mechanism in which charge transfer was blocked by the adsorption of TRE molecules on the iron surface [21]. It also revealed that the whole process was controlled by the surface reaction since the energy of the activation corrosion process in presence of TRE was nearer to $20 \mathrm{~kJ} \mathrm{~mol}^{-1}$.

As seen in Table 4, the values of $\Delta \mathrm{H}^{*}$ were approximate, and the values of $\mathrm{Ea}$, increased for the corrosion of iron in the presence of inhibitor by up to $80 \%$, indicating that the energy barrier for the corrosion reaction increased in the presence of inhibitor without change of the dissolution mechanism [22]. The entropy of activation, $\Delta \mathrm{S}^{*}$, was negative both in the absence and presence of inhibitor, implying that the activated complex represented the rate-determining step with respect to the association rather than the dissociation step. This implies that a decrease in disorder occurred when proceeding from statc of reactants to the activated complex [23].

In addition, the less negative values of $\Delta S^{*}$ in the presence of inhibitor imply that the presence of inhibitor created a quasi-equilibrium corrosion system state.

TABLE 4. values of activation parameters $\Delta S *$ and $\Delta H^{*}$ for iron $0.5 \mathrm{MHCl}$ in the presence and absence of various inhibition concentrations.

\begin{tabular}{ccccc}
\hline Inhibitor & $\mathbf{C}(\mathbf{g} / \mathbf{1 0 0} \mathbf{m l})$ & $\mathbf{E a}(\mathbf{k J} / \mathbf{m o l})$ & $\Delta \mathbf{H}^{*}(\mathbf{k J} / \mathbf{m o l})$ & $\Delta \mathbf{S}^{*}(\mathbf{J} / \mathbf{m o l})$ \\
\hline $0.5 \mathrm{M} \mathrm{HCl}$ & ---- & 7.69 & 5.22 & -275.37 \\
& 2.0 & 10.02 & 7.55 & -275.83 \\
Turmeric Root & 4.0 & 15.99 & 13.52 & -258.93 \\
extract (TRE) & 6.0 & 18.99 & 16.52 & -251.65 \\
& 8.0 & 18.43 & 15.96 & -255.51 \\
\hline
\end{tabular}

Adsorption isotherm

Adsorption isotherm study describes the adsorptive behavior of organic inhibitors to understand the adsorption mechanism. The most usually applied adsorption isotherms are Frumkin, Temkin, and Langmuir. The surface coverage $(\Theta)$ values for the inhibitor concentration used were calculated using polarization measurements.

Langmuir adsorption isotherm was tested and found most appropriate isotherm to fit the experimental data. Langmuir adsorption isotherm is represented by the following equations [24]:

$\log (\Theta / 1-\Theta)=\log \mathrm{K}+\mathrm{Y} \log \mathrm{C}$

Rearrangement gives the following equation

$\mathrm{C} \backslash \theta=1 / \mathrm{K}_{\mathrm{ads}}+\mathrm{C}$

Where, $\theta$ is the degree of surface cover with the inhibitor, $\mathrm{Y}$ is the slope; number of layers. $\mathrm{K}_{\text {ads }}$ is the adsorption equilibrium constant and $\mathrm{C}$ is the 
concentration of inhibitor used in the corrosive medium.

A straight line was obtained by plotting $\mathrm{C} / \Theta$ vs $\mathrm{C}$ with the $\mathrm{R}^{2}$ value almost unity (0.99) (Fig. 10).
The calculated slope is almost unity suggesting that the Langmuir adsorption isotherm model provides the best description of the adsorption behavior.

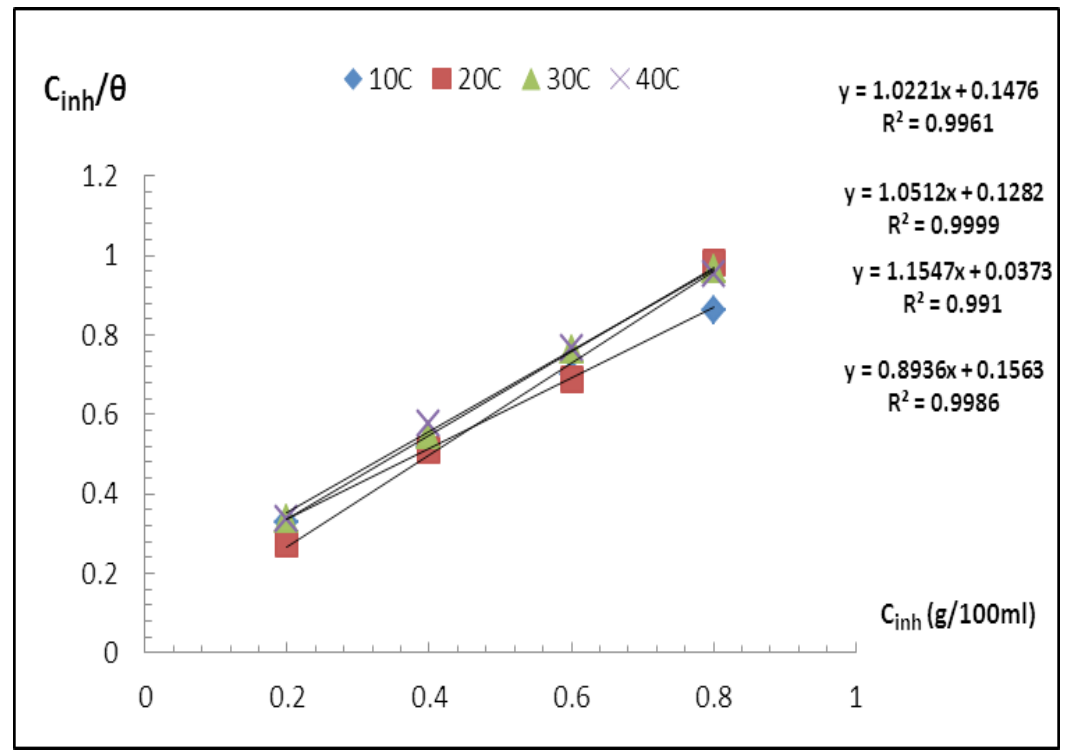

Fig. 10. Plots of Langmuir adsorption isotherm of TRE on iron surface at different temperatures.

TABLE 5. Calculated parameters of Langmuir adsorption isotherm.

\begin{tabular}{|c|c|c|c|c|c|}
\hline $\mathbf{T}(\mathrm{K})$ & $1 / K$ & $\Delta \mathrm{Ga}\left(\mathrm{kJmol}^{-1}\right)$ & $\Delta \mathrm{Sa}\left(\mathrm{Jmol}^{-1}\right)$ & $\mathbf{R}^{2}$ & $\Delta \mathrm{Ha}\left(\mathrm{kJmol}^{-1}\right)$ \\
\hline 283 & 0.16 & -13.8169 & 48.75 & 0.9986 & \multirow{4}{*}{-20} \\
\hline 293 & 0.04 & -17.7954 & 60.67 & 0.9910 & \\
\hline 303 & 0.13 & -15.2926 & 50.40 & 0.9999 & \\
\hline 313 & 0.15 & -15.4306 & 49.24 & 0.9961 & \\
\hline
\end{tabular}

Value of up to $-20 \mathrm{~kJ} \mathrm{~mol}^{-1}$ is consistent with the electrostatic interaction between the charged molecules and the charged metal (physical sorption), while values more negative than $-40 \mathrm{~kJ}$ $\mathrm{mol}^{-1}$ involves sharing or transfer of electrons from the inhibitor molecules to the metal surface to form a coordination type of bond (chemisorption) [25]. In the present study, the value of $\Delta \mathrm{Ga}$ is less than $-20 \mathrm{~kJ} \mathrm{~mol}^{-1}$ which is an indication that physical adsorption in dominant.

\section{SEM-EDX analysis}

Surface morphology of iron was studied by scanning electron microscopy after $1 \mathrm{~h}$ immersion in $0.5 \mathrm{M} \mathrm{HCl}$ with and without addition of the inhibitor. Figure 11(a) represents the micrograph obtained of polished steel before exposing to the corrosive medium while Fig. 11(b) showed strongly damaged steel surface due to the corrosion effect after immersion in $0.5 \mathrm{M} \mathrm{HCl}$ solution. SEM images of steel surface after 1hour immersion in $0.5 \mathrm{M} \mathrm{HCl}$ with $1 \mathrm{~g} / 100 \mathrm{ml} \mathrm{TRE}$ is shown in Fig. 11(c). It can be seen from Fig. 11a that the iron sample before immersion seems smooth and shows some abrading scratches on the surface. Inspection of Fig. $11 \mathrm{~b}$ reveals that the iron surface after immersion in uninhibited $0.5 \mathrm{M}$ $\mathrm{HCl}$ shows an aggressive attack of the corroding medium on the iron surface. In contrast, in the presence of $1 \mathrm{~g} / 100 \mathrm{ml}$ TRE (Fig. 11c) the iron surface was corroded only negligibly. In addition, there was an adsorbed film on the iron surface that was not observed in Fig. 11b. These results confirmed enhancement of surface coverage of steel surface that led to decrease in contact between the iron and the aggressive medium. Thus, a good adsorptive protection layer that was formed by the inhibitor can efficiently inhibit corrosion of steel. 


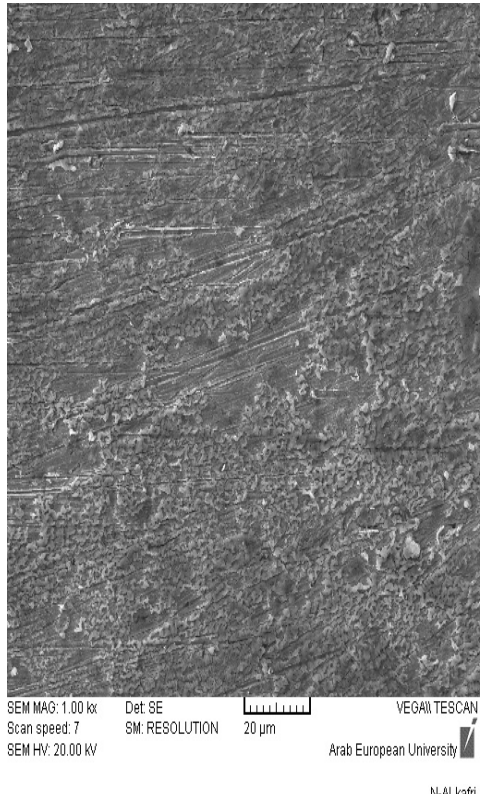

(a)

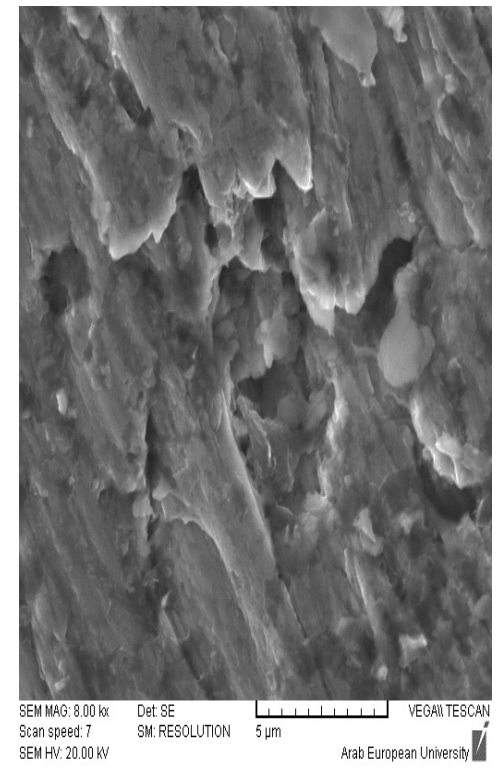

(b)

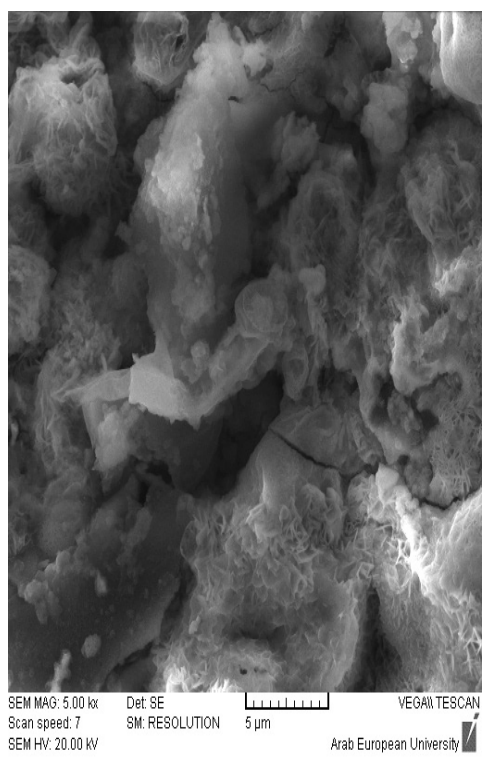

N.ALkafir

(c)

Fig. 11. SEM of polished iron (a) before immersion (b) after 1 hour of immersion in $0.5 \mathrm{M} \mathrm{HCl} 1 \mathrm{~g} / 100 \mathrm{ml}$ of TRE, and (c) Treated iron in the presence of $1 \mathrm{~g} / 100 \mathrm{ml}$ extract.

The following table shows the percentages of

of TRE.

the studied elements in the presence and absence

TABLE 6. The percentages of the studied elements in the presence of TRE.

\begin{tabular}{lccc}
\hline Element & C & O & Cl \\
\hline Without inhibitor & 0.20 & ---- & ----- \\
After adding 0.5 M HCl & 0.20 & 29.86 & 1.76 \\
With inhibitor & 26.84 & 7.14 & 0.1 \\
\hline
\end{tabular}

The iron surface is analyzed at different points of the surface using an energy dispersive x-rays technique. Since the inhibitor contains mainly carbon and oxygen atoms, and the corrosive media is $0,5 \mathrm{HCl}$, the variation of carbon, oxygen and chlorine atoms weight percentage on the surface can be used quantitatively to explain the adsorption of the inhibitor on the iron surface. In the presence of the extract the weight percentage (wt. \%) of carbon increased while chlorine decreased, as that the atom of oxygen is higher in the presence of the corrosive media composed to the polished and treated iron, as shown in Fig. 12. Thus it can be concluded that there is a good protective layer on the surface of iron is responsible for inhibition.

\section{Conclusion}

The following results can be mentioned briefly:

1- The inhibition efficiency (IE\%) of TRE increases with increase of extract concentration.

2- EIS results showed that the double layer capacitance $\left(\mathrm{C}_{\mathrm{d1}}\right)$ decreases and charge transfer resistance $\left(\mathrm{R}_{\mathrm{ct}}\right)$ increases with time of immersion in the extract.

3- The inhibitor showed maximum inhibition efficiency (IE\%) $88.9 \%$ at $8 \mathrm{~g} / 100 \mathrm{ml}$ concentration.

4- The inhibition efficiency (IE\%) of TRE decreased with temperature, which leads to a decrease in activation energy (Ea) of the corrosion process.

5- The activation energy value of Ea $=-20 \mathrm{kJmol}^{-1}$ indicates that the adsorption process is spontaneous and is physical adsorption.

6- Langmuir adsorption isotherm and SEM studies showed that TRE inhibitions occur through adsorption mechanism.

7- The results of SEM and EDX, have been shown to form a protective film on the iron surface. 

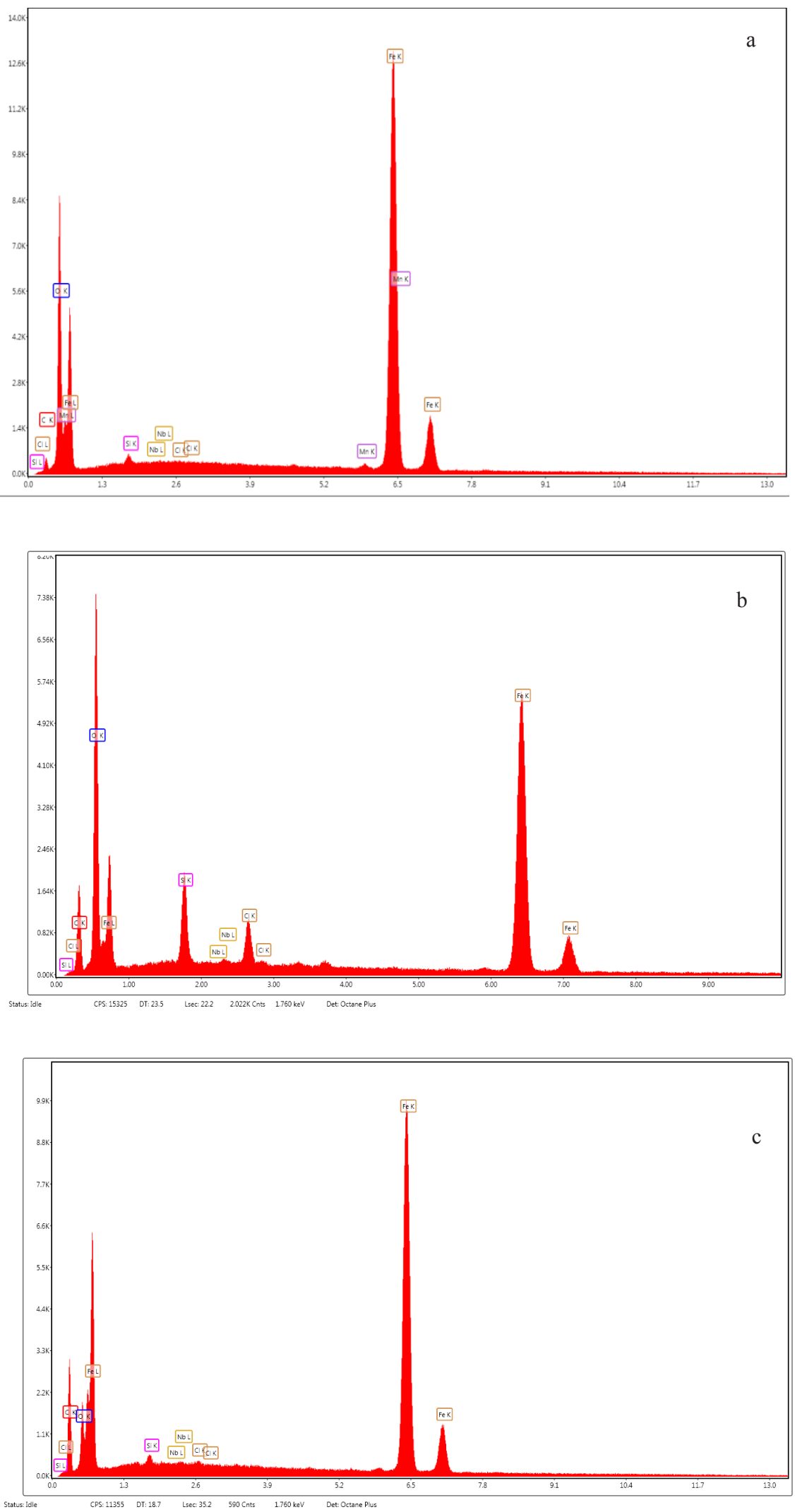

Fig. 12. EDX of (a) polished iron ; (b) after 1 hour of immersion in $0.5 \mathrm{M} \mathrm{HCl}$, and (c) Treated iron in the presence of $1 \mathrm{~g} / 100 \mathrm{ml}$ extract.

Egypt.J.Chem. 62, No. 3 (2019) 


\section{Acknowledgment}

I thank everyone who helped in the face of this work, from laboratory professors and the Atomic Energy Commission.

\section{References}

1. Ahmed A., Amir H. Kadhum and Abdulhadi K., Inhibition of mild steel corrosion in sulfuric acid solution by new Schiff base. Process Engineering, University Kebangsaan Malaysia., 7, 787-804 (2014).

2. Ferreira, E.S., Giacomelli, C., Giconelli, F.C. and Spinelli, A., Evaluation of the inhibitor effect of L-Ascorbic acid on the corrosion of mild steel. Materials Chemistry and Physics, 83, 129-134 (2004).

3. Bentiss, F. Gassama, D. Barbry, L. Gengembre, H. Vezin, M. Lagrene'e, Traisnel M., Corrosion inhibition of mild steel in acidic media using newly synthesized heterocyclic organic molecules: Correlation between inhibition efficiency and chemical structure. Appl. Surf. Sci. 252 (2006).

4. Lagrenee, M, B. Mernari, N. Chaibi, M. Traisnel, H. Vezin and Bentiss F., Corrosion inhibition of mild steel in acidic media using newly synthesized heterocyclic organic molecules: Correlation between inhibition efficiency and chemical structure. Corros. Sci. 43 (2001).

5. Ayers, R.C., Jr. Hackerman, N., Corrosion inhibition in $\mathrm{HCl}$ using methyl pyridines. $J$. Electrochem. Soc., 110 (6), 507-513 (1963).

6. Moretti, G., Guidi, F. and Grion, G., Tryptamine as a green iron corrosion inhibitor in $0.5 \mathrm{M}$ deaerated sulphuric acid. Corrosion Sci., 46 (2), 387- 403 (2004).

7. Quraishi, M. A., Rawat, J. and Ajamal, M., Dithiobiurets: A novel class of acid corrosion inhibitors for mild steel. J. Appl. Electrochem., 30 (6), 745- 751 (2000).

8. Khalil, N., Quantum Chemical Approach of Corrosion Inhibition. Electrochimica Acta, 48, 2635- 2640 (2003).

9. Johnsirani, V. J. Sathiyabama, S. Rajendran and Nagalakshmi R., Curcumin dye as corrosion inhibitor for carbon steel in sea water. Chem. Sci. Trans. 744-753 (2013).

10. Abdel-Gaber, Khadija M. Hijazia, Ghassan O. Younesa and Bilal Nsouli., Comparative study of the inhibitive action between the bitter orange leaf extract and its chemical constituent linalool on the mild steel corrosion in HCL solution. 230 (2017).

11. Mohamed, H.A., Farag, A.A. and Badran,
B.M. Corrosion Inhibition of Mild Steel Using Emulsified Thiazole Adduct in Different Binder Systems. Department of Polymers and Pigments, National Research Center, Cairo, Egypt, 10, 67-77 (2008).

12. Abdel Hamid, Z., Clarification of the corrosion inhibition of mild steel in hydrochloric acid solutions via cetyltrimethyl ammonium bromide inhibitor. Helwan and Department of Chemistry, Faculty of Science, Benha University, Benha, Egypt J. Chem. 57 (5,6), 353-371 (2014).

13. Shukla, S. K., Quraishi M. A., The effects of pharmaceutically active compound doxycycline on the corrosion of mild steel in hydrochloric acid solution (HCl). Corros. Sci. 52, 314 (2010).

14. Benali O. L. Larabi, M. Traisnel, L. Gengembra, Y. Harek, Study on the inhibition of mild steel corrosion by quaternary ammonium compound in $\mathrm{H}_{2} \mathrm{SO}_{4}$ medium. Appl. Surf. Sci. 253, 6130 (2007).

15. Yurt, A. Balaban, S. Ustun Kandemir, G. Bereket, B. Erk, adsorption and corrosion inhibition characteristics of some nicotinamide derivatives on mild steel in hydrochloric acid solution ( $\mathrm{HCl})$. Mater. Chem. Phys. 85 (2004).

16. Abd EI-Rehim, S, M. A. M. Ibrahim, K. F. Khaled, J., 4-Aminoantipyrine as an inhibitor of mild steel corrosion in $\mathrm{HCl}$ solution. Appl. Electrochem. 29 (1999).

17. Wen-Ming Ch, Post F, Joshua L, Suresh., Sazzadur R, and Anjali T., Sub-surface Corrosion Research on Rock Bolt System, Perforated SS Sheets and Steel Sets for the Yucca Mountain Repository. 30 (2004).

18. Bentiss,F, M. Bouanis, B. Mernari, M. Traisnel, H. Vezin, M. Lagrenee, Appl. Surf. Sci. 253 (2007).

19. Ehteram A. Noor, Aisha H. Al-Moubaraki Thermodynamic study of metal corrosion and inhibitor adsorption processes in mild steel/1methyl-4[4_(-X)-styryl pyridinium iodides/ hydrochloric acid systems, Mater. Chem. Phys. 110, 145- 154 (2008).

20. Sayyah, S.M., Abd El-Rehim, M.M., Mohamed S.M., Corrosion inhibition of aluminium with a series of aniline monomeric surfactant and their analogues polymers in $0.5 \mathrm{M} \mathrm{HCl}$ solution. Chemistry Department, Faculty of Science, Ain Shams University, Cairo, Egypt J. Chem. 55 (6), 583- 602 (2012).

21. Maqsood A., M., Ali H., Firdosa N., Shaeel Ah, Zaheer Kh., Anti-corrosion ability of surfactants. Int. J. Electrochem. Sci., 6, 1927 - 1948 (2011).

22. Abd El-Rahim, S. S., M Refaey, S. A., Taha,

Egypt.J.Chem. 62, No. 3 (2019) 
F. B., Saleh, M., Ahmed, R. A., Novel cationic surfactants from fatty acids and their corrosion inhibition efficiency for carbon steel pipelines in $1 \mathrm{M} \mathrm{HCl}$. J. Appl. Electrochem. 31 (2001).

23. Abd El-Rehim, S. S., Hassan, H. H., Amin, M. A. Corrosion inhibition of aluminum in hydrochloric acid solution $(\mathrm{HCl})$ using potassium iodate inhibitor. Mater. Chem. Phys. 70 (2001).

24. Bilgic, S., Caliskan N., Inhibition of steel corrosion in hydrochloric acid solution $(\mathrm{HCl})$ by chamomile extract. Appl. Surf. Sci 152 (1999).

25. Tsuru, T. Haruyama, S. Gijutsu, B., Corrosion monitor based on impedance method; construction and its application to homogeneous corrosion, Jpn. J. Soc. Corros. Eng 27 (1978).

(Received 4/10/2018, accepted 3/12/2018)

مطيافية المعاوقة الكهروكيميائية (EIS) ودراسة تثبيط تأكل الحديد باستخدام جذور الكركم (TRE)

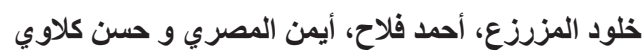
قسم الكيمياء ـ كلية العلوم - جامعة دمشق - سوريا.

دُرس تأثثر مستخلص جذور نبات الكركم (TRE) في تثبيط تأكّل الحديد في وسط من حمض كلور الماء (0, .

(HCl

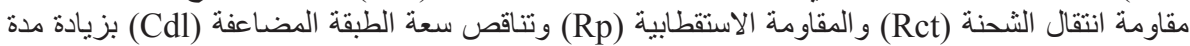

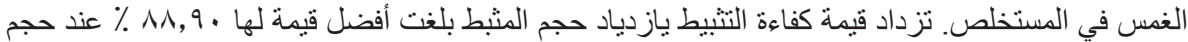

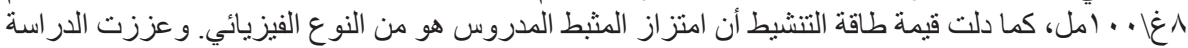

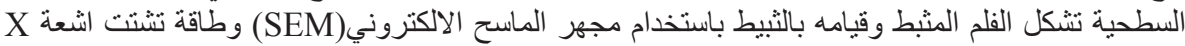

.(EDX) 